\title{
An Approach of Track Managements System in Software Defined Radar
}

\author{
Zvonko Radosavljević ${ }^{1)}$ \\ Dejan Ivković ${ }^{1)}$
}

\begin{abstract}
Each multi target tracking system must have a track management procedure. It is an integral part of tracking systems and often used together with data association, state estimation and other parts of systems. On the other hand, the family of C-band frequency agile, low to medium altitude pulse Doppler air search radars, are designed to detect low-altitude, low cross-section aircraft targets in conditions of clutter and electronic countermeasures. Within the framework of its modernization, the receiver is conceived on the basis of software defined radar. The implementation of target tracking system within software defined radar, is also suggested. The paper describes the procedure of track management system procedure in the framework of multi target tracking system. It includes complete procedure of initialization, maintenance and deletion of tracks. Part of the numerical experiments is given at the end of the paper, in order to describe a good property functional of the TMS system
\end{abstract}

Key words: target tracking, target tracking radar, software defined radar, track management, numerical simulation, procedure.

\section{List of Acronyms}

$\begin{array}{ll}\text { A/D } & \text { - Analog to Digital } \\ \text { C2 } & - \text { Command and Control System } \\ \text { DSP } & \text { - Digital Signal Processor } \\ \text { GNN } & \text { - Global Nearest Neighbor } \\ \text { IF } & \text { - Intermediate Frequency } \\ \text { IMM } & \text { - Interacting Multiple Model } \\ \text { KF } & \text { - Kalman Filter } \\ \text { MTT } & \text { - Multi Target Tracking } \\ \text { NI } & - \text { National Instruments } \\ \text { PRF } & - \text { Pulse Repeat Frequency } \\ \text { RF } & - \text { Radio Frequency } \\ \text { SHORAD } & - \text { Short Range Air Defense } \\ \text { MTI } & - \text { Military Technical Institute } \\ \text { SDR } & - \text { Software Defined Radar } \\ \text { FPGA } & - \text { Field Programmable Gate Array } \\ \text { TWT } & - \text { Traveling Wave Tube } \\ \text { TMS } & - \text { Track Management System }\end{array}$

\section{Introduction}

$\mathrm{I}_{\mathrm{N}}^{\mathrm{N}}$ $\mathrm{N}$ a multi-target tracking algorithm, it is assumed that the number of tracks is known a priori [1]. This is almost never true in practice. The tracks appear and disappear as objects come into and go out of the range of a sensor. Tracks may also coalesce when two or more objects become irresolvable close in the sensor's measurement space. The number of tracks must be adjusted [2,3].

At each scan, the measurements are received from the radar sensor and are added to the set of measurements; the oldest scan of data is dropped from the set of measurements. These new measurements are processed by the target tracking algorithm which updates the entire track estimates. Various algorithms can use, depending on the type of sensor data measurements and data preprocessing: linear or non-linear [4, 5].

At this time, many types of C-band family of land and naval two - or three - dimensional passive electronically scanned array radar-based systems are enabled for surveillance and air defense command and control. Systems are tailored for operations with medium and short range air defense missile or gun systems or for use as gap-fillers in a larger air defense system [6]. The radar gets its name from the distinctive folding mast which, when deployed, allows the radar to see over nearby terrain features such as trees, extending its effective range against low-level air targets. The first systems were produced in 1977. Radar GIRAFFE is designed to detect low-altitude, low cross-section aircraft targets in conditions of severe clutter and electronic countermeasures. When equipped as an air-defense command center the Giraffe provides an air picture to each firing battery using man portable radio communication. This enables GIRAFFE to act as a command and control center in air defense system, it can also be integrated into a sensor net for a greater coverage. It is normally housed in a single $6 \mathrm{~m}$ long shelter mounted on an all-terrain vehicle for high mobility.

In this paper, we used standard Global Nearest Neighbor (GNN) algorithm. In order to increase accuracy of tracks (track position and velocity) we proposed the Interacting Multiple Model [7]. If any new tracks are found, the initial parameter estimates for these tracks are extracted from the curves corresponding to the points detected in the normalized set of measurements $[8,9]$.

\section{Problem Statements}

Family of C-band, low to medium altitude pulse Doppler air search radars, are often used to detect low-altitude, low cross-section aircraft targets in conditions of dense clutter.

\footnotetext{
1) Military Technical Institute (VTI), Ratka Resanovića 1, 11132 Belgrade, SERBIA

Correspondence to: Zvonko Radosavljević; e-mail: zvonko.radosavljevic@gmail.com
} 
Within the framework of the modernization of this type of radars, the receiver is conceived on the basis of the SDR (software defined radar). Military Technical Institute, Belgrade, purchased a license for GIRAFFE 75 and worked on a new model with several modifications. Radar GIRAFFE is a family of C-band frequency agile, pulse Doppler air search radars which can be used in mobile or static short to medium range air defense applications. Domestic Serbia designation is M85 "ŽIRAFA" on chassis of FAP 2026 [6].

During the modernization of the radar GIRAFFE, we performed the implementation of SDR for the radar data receiving and processing.

\section{Concept of the Radar Giraffe}

Radar GIRAFFE (Fig.1) is intended to detect and track low targets within the Air Defense System and to send target coordinates to the BOFORS (BAE Systems AB-Sweden) system. The radar detects the distance and azimuth of the target. Target speed is not measured, but roughly estimated through the tracking circle, and the targets are ranked in only three groups of speeds. The maximum radar detection range is $40 \mathrm{~km}$. As a power amplifier, a Traveling Wave Tube pipe is used, which ensures that the radiated power in one pulse is 15 $\mathrm{kW}$. The Pulse Repeat Frequency is variable and can be changed every second, from one to another revolution of the antenna ("variable $P R F^{\prime \prime}$ ), or from one to another transmitting pulse ("multiple $P R F^{\prime \prime}$ [ [8].

\section{Software Defined Radar}

Because of high level of flexibility the software radar has many advantages in comparison to conventional radar. Also, service of the software radar system is much cheaper. The concept of the software radar represents a specific application of the software radio.

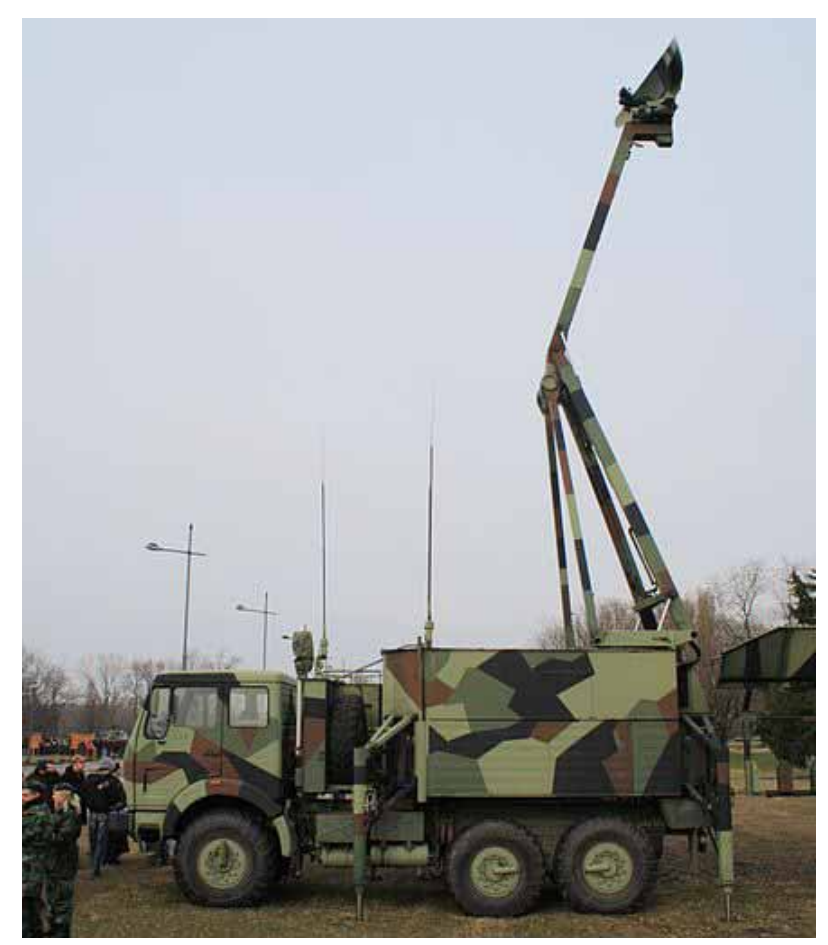

Figure 1. External appearance of Radar GIRAFFE

The intermediate frequency in the receiver is $30 \mathrm{MHz}$. GIRAFFE can detect targets moving at speeds of 15 to 900 $\mathrm{m} / \mathrm{s}$ with a resolution of $740 \mathrm{~m}$ in maximum operating mode. This resolution is very modest for today. Azimuth resolution is $4.7^{\circ}$. The radar antenna is in the form of a partial paraboloid. The radiation diagram is square cosecant with a beam width of azimuth $2.1^{\circ}$ and elevation of $9.2^{\circ}$. The gain of the antenna is $28 \mathrm{~dB}$, and the height of the ground is $13 \mathrm{~m} \mathrm{[9}$, $10]$.

Software radar is first mentioned at the end of the last decade of the twentieth century, as a radar device whose functions are software-defined. Software radar must be flexible, reprogrammable, to enable the management of various communication protocols and operation at different frequencies, while using the same hardware platform under software control. By $\mathrm{s}$ implying the change, update or replacement of the software, the radar functions and characteristics can be completely changed and improved. In this way, the radar device is easy to modernize, because the application of the most modern radar signal processing techniques can be implemented very quickly without major hardware changes.

The functions of the digital radar system, which are most commonly implemented by the software, are signal processing, transmitted signal waveform generating, control of the antenna system operation and synchronization of all functional units of the system. Also, work must be provided in real time.

Since complicated mathematical calculations are performed while processing the signal, processing on fast DSP (Digital Signal Processor) or FPGA (Field Programmable Gate Array) boards is necessary. Software radar provides very good data display capabilities based on the processed signals and target detection.

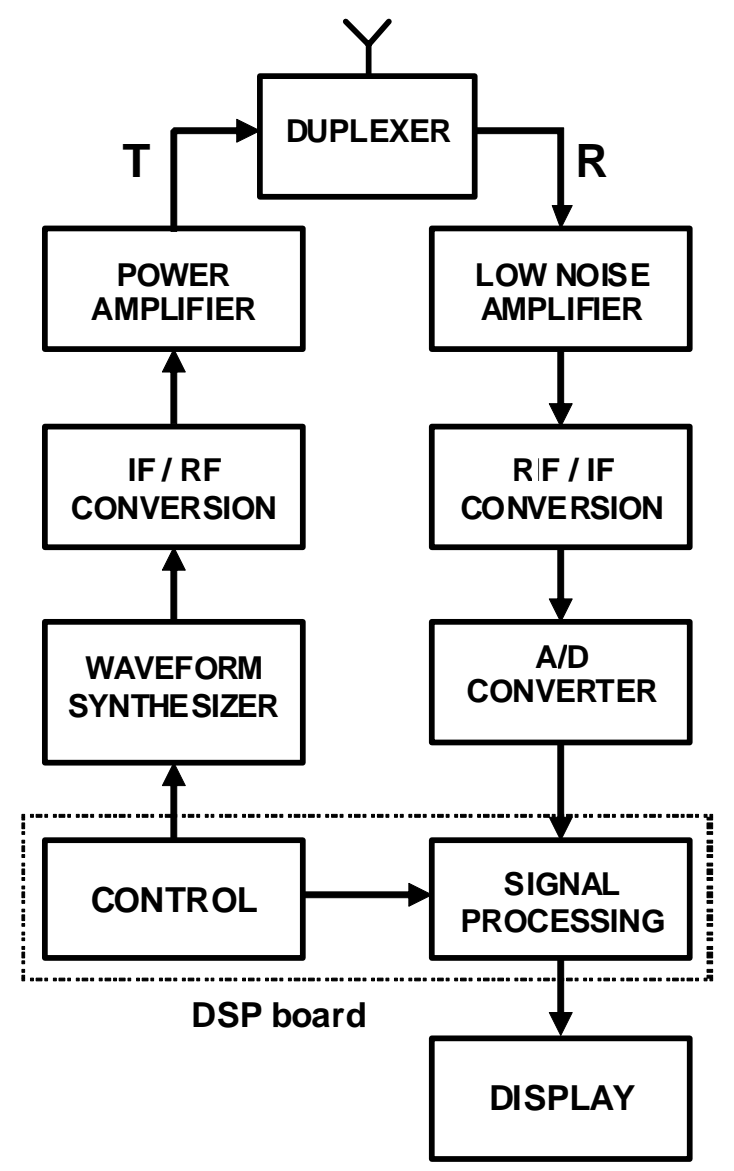

Figure 2. Software radar system

It is possible to select and mark the affiliation of the target, which is especially important for radars used for military purposes, which must distinguish their own aircraft from civilian or enemy airplanes. It is much easier to feasibly draw a trajectory of selected goals and associate different symbols 
for different target classes. The target classes are selected according to the purpose of the system.

The general scheme of software radar is shown in Fig.2. Each block consists of modular components, so it is possible to combine components, in order to achieve the desired function.

A block called waveform synthesizer generates an appropriate transmitted signal of a pulse or continuum nature that will modulate the hyper frequency carrier. This block of software radar is flexible, which means that the transmitted signal shape can be changed during operation. For radars working with signals in a spread spectrum, the wavelength synthesizer generates a forward signal that is encoded by frequency or phase, which contributes to improved resolution at a distance. Next, an IF/RF conversion block, the spectrum of the generated signal should be transmitted to the hyperfrequency range of the gigahertz level. This is most often accomplished by multiplying the frequency of the quartz oscillator signal.
This is followed by a high-frequency solid state power amplifier that should have as much amplification as a very small noise factor so that the distortion of the transmitted waveform is reduced. Block duplexer is actually an antenna switch that, by pulsed radar, directs electromagnetic energy to the antenna, at time intervals as the radar transmits signal. At time intervals when no radar signal is transmitted, the duplexer passes all the signals at the antenna input to the receiving channel [11].

As with the conventional radars, the low noise amplifier is also the first block in the receiving branch of radar here. Its name indicates that it is an amplifier with a small noise factor, and it is desirable to have as much amplification as possible. The RF/IF conversion block has the opposite function of the IF/RF conversion block. Namely, the spectrum of the receiving signal is transferred from the hyper-frequency domain to the intermediate frequency range that is usually the order of several tens of megahertz to facilitate digital signal processing.

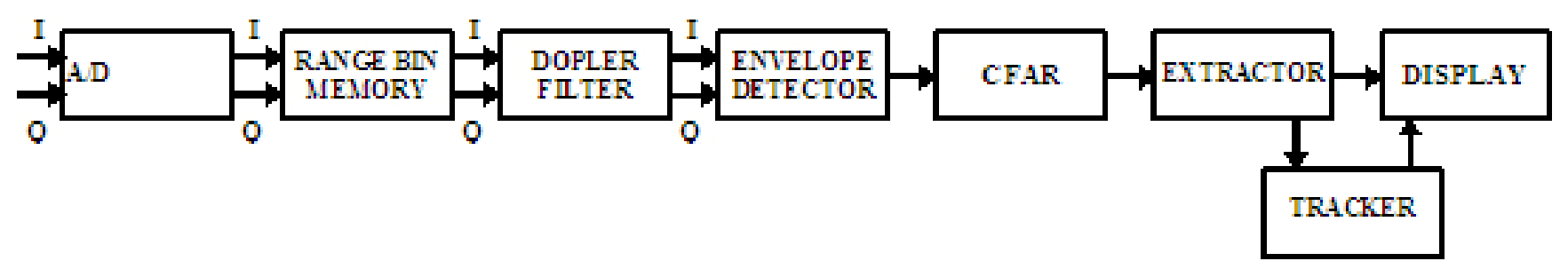

Figure 3. Block diagram of the used SRR

The analog-to-digital (A/D) converter has numerous applications in modern radars, and especially in software radars. For example, in the MTI radar (Moving Target Indication) that selects moving targets, an $\mathrm{A} / \mathrm{D}$ converter is required with frequencies of sampling around several megahertz, and even larger ones. Here the signals at the exit from the synchronous detector are selected at a speed that must not be less than the width of the bandwidth of the receiver, and for the storage of digitized data a memory with a capacity of the order of gigabytes is required. Fast $A / D$ converters are also required for radar for automatic tracking of targets, and also for multipath radars that reach the target coordinates through arithmetic interpolation.

By the software radar, the output of the A/D converter is directly coupled to the signal processing block, which together with the control block forms the central part of the software radar, i.e. DSP or FPGA board. The DSP or FPGA board represents the central control unit of the whole system. Most importantly, it provides digital signal processing in real time. In addition to processing the DSP or FPGA signal, the board performs another important function, which is data processing.

Processed data needs to be converted to a suitable format to display to the user of the radar device on the appropriate display. The display of software radar is the most common computer monitor, which in itself speaks of much better possibilities of displaying the received information about objectives and greater transparency, which makes it easier to operate the system.

On the basis of software radar concept we realized a functional model of software radar receiver (SRR) from A/D converter to display. The block diagram is shown in Fig.3.

After IQ demodulator A/D (Analog to Digital) converter follows and then blocks which are first programmed in MATLAB ${ }^{\circledR}$ software follow, then those projected in $L a b$ VIEW and in the end those implemented on the PXI (PCI
eXtensions for Instrumentation) platform. All blocks in Fig.3 are realized with the following hardware components:

- National Instruments PXIe-1065,

- National Instruments PXIe-7962R FlexRIO FPGA Module for PXI Express,

- National Instruments 57344 Channel Digitizer Adapter Module for NI FlexRIO and

- National Instruments PXIe-8133 1.73 GHz Quad-Core PXI Express Controller.

The component NI PXIe-1065 is 18-Slot 3U PXI Express Chassis designed for a wide range of test and measurement applications. It provides a high-bandwidth backplane with up to $1 \mathrm{~GB} / \mathrm{s}$ per-slot dedicated bandwidth.

The component NI PXIe-7962R is FPGA (FieldProgrammable Gate Array) module which provides flexible, customizable I/O for NI LabVIEW FPGA. It has a digital signal processing focused Virtex-5 SX50T FPGA and $512 \mathrm{MB}$ of onboard DDR2 DRAM.

The component NI 5734 is $\mathrm{A} / \mathrm{D}$ (analog to digital) converter. It can process 4 simultaneously sampled 16-bit channels.

The component NI PXIe-8133 is $1.73 \mathrm{GHz}$ Quad-Core PXI Express Controller. It is Intel Core i7-820QM processorbased embedded controller for use in PXI Express systems. It is ideal for processor-intensive, modular instrumentation, and data acquisition applications.

Fig. 4 shows the moment of detection of one real target. On the original real radar display left a target can be seen at a range of $10 \mathrm{~km}$ and azimuth $240^{\circ}$ which is surrounded by a large number of false targets/detections. It is clear that the surrounding bright spots are not targets, because those appear on completely different coordinates in the next antenna revolutions. With the setting of the parameters in realized functional model, in this case in an extractor, on the realized radar display (right in Fig.4) there are no false targets but only real radar target. 


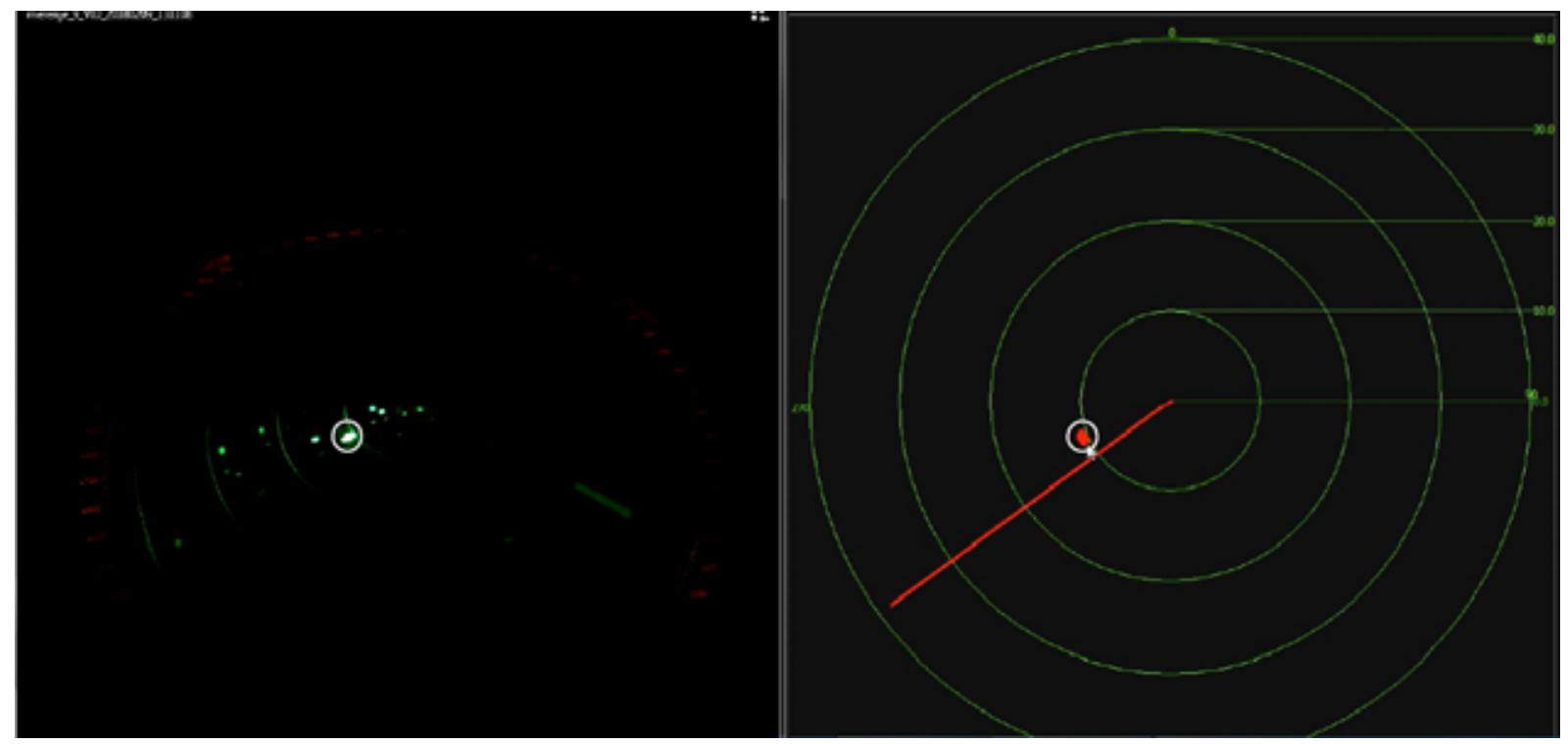

Figure 4. Real and new realized radar display

All tests in laboratory conditions with simulated radar signals and tests with real radar signals in a real radar have shown that a realized functional model of SRR detects radar targets correctly both in azimuth and range. Signal processing is realized in real time without any delays.

\section{Track management procedures}

A radar tracker is a component of a radar system, or an associated Command and Control (C2) system, which associates consecutive radar observations of the same target into tracks. In an automatic object tracking system, tracks are initialized and updated using measurements [11]. A track may "lose" its object due to an unfavorable detection sequence, object maneuvers, clutter measurements, measurement noise, multiobject effects or some combination thereof. The target that was followed by a true track may physically disappear from the surveillance area due to terminating its trajectory, entering an observation shadow, actually disappearing or simply departing the surveillance space [12].

A Track Management System is developed to support any target tracking algorithm that follows issues:

- detection and initiation of new tracks;

- track maintenance and deletion

- merging of estimates closing track (two or more tracks),

- removal of tracks that correspond to objects that have moved outside the sensor's range.

Basically, one multi-target radar tracker iteration contains:

- Initialization: The radar and tracking parameters are initialized

- Read measurements: At the beginning of each new iteration, all received measurements for the new scan are read,

- Kalman Filter estimate: KF track state estimate of all existing tracks (if exists) is calculated,

- Old measurements: All measurements from the previous scan, which have not been selected by some of the existing tracks, are declared by non-selected measurements they are returning to the new iteration,

- Initiate new tracks: New tracks are initiated on the basis of new measurement of gates of old measurements, which are the old tracks updated on the same principle,

- Gating and data association: New measurements are found in the gates of the prediction track from the previous scan, and with the GNN only one (if any) is assigned to the track,
- Tracks confirmation: Measurements in the gates of the existing track extend the duration of the track. Other measurements, which are not identified as belonging to existing tracks, are declared for non-selected measurements and are transferred to the next iteration,

- Update status: One possible track status is updated (confirmed, tentative or eliminated)

- A Kalman Fiter prediction: track state prediction is performed for all tracks, for the next scan (or iteration),

- Return to the beginning: Return to the beginning of the iteration.

As a special feature for this TMS procedure, there is a measIn parameter, 'measurement that comes from the target'. This parameter directly affects the status of the track and can have three states:

- gate measurement,

- no gate measurement,

- empty measurement.

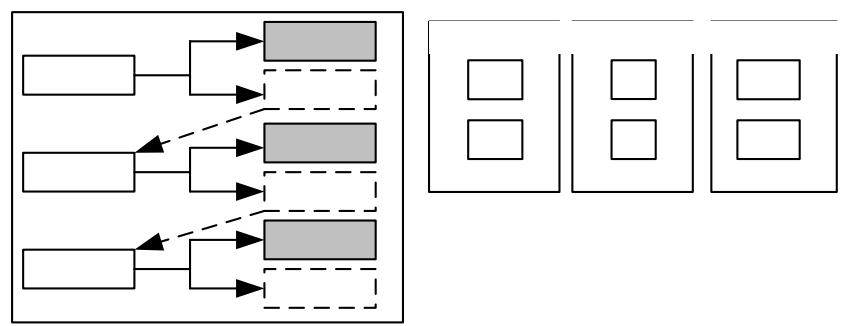

Figure 5. Track status parameter

Basically, the complete TMS procedure is defined with four parameters, given in Fig.5. These are:

- measIn, the measurements status parameter which can have one of the three levels which means that in the gate of the measurement (or track estimate) there is a measurement that belongs to the current track, symbol $[0,0]$ - which means that in the current scan there are no measurements belonging track, while in the previous one thereafter, symbol [] -meaning that in the current scan there are no measurements belonging to the track, although they were not present in the previous scan,

- confirmed, track status parameter, occurs when new measurements are falling in the gate of the existing (or initialized) track,

- tentative, track status parameter, occurs when confirmed track does not contain measurements in gate, 
- eliminated, track status parameter, occurs when track has status measIn=[] (no new measurements that are falling in the gate of the track), confirmed $=1$ and tentative $=1$, in the previous scan. After this status, the track is terminated. This process can be described by the following: each measurement can be a potential track. When a new measurement appears in the gates of the "old" measurement, it is proclaimed. Basic sub-activities, in order to perform quality and accurate track managements system are:

- track detection and initialization,

- track maintenance and deleting,

- track merging,

- removing old tracks,

- track smoothing, and

- measurements to track association

\section{Detection and Initialization}

Track initiation is the process of creating a new radar track from an unassociated radar plot. The management procedure for detecting and initializing of a track involves finding the measurements along the track's trajectory. Since the trajectories of new tracks are unknown, a finite set of path integrals along curves that are assumed to approximate target trajectories can be performed and threshold to determine the presences of tracks.

Typically a new track is given the status of "tentative" until plots from subsequent radar updates have been successfully associated with the new track (tentative tracks are not shown to the operator). After several scans have been received, the track is given status of "confirmed" and displayed to the operator.

\section{Track Maintenance and Deleting}

Track maintenance and deleting is the process in which a decision is made about whether to end the life of a track. If a track was not associated with a plot during the plot to track association phase, then there is a chance that the target may no longer exist, and it is deleted in the next scan. Basic approaches to decide on whether to maintenance or to terminate a track include:

- target has not been seen for the previous $T_{M}$ consecutive scans (for example $T_{M}=3$ )

- target has not been detected for the previous $T_{M}$ of N most recent scans,

- target's track uncertainty has grown beyond a certain predefined threshold.

\section{Tracks Merging}

The need to merge one or more tracks can arise because multiple new tracks have converged on the same target or one or more targets cannot be separated using the measurements received by the sensor. Two or more targets are on the same azimuth angle, but target distance is different. Pairs of tracks that need to be merged are detected using the statistics.

\section{Removing Old Tracks}

At some point in time, the tracked target will no longer be visible to the sensor. Every time this occurs, the corresponding tracks must be removed from the track list. A simple scheme to recognize tracks that need to be deleted is to require that a minimum number of measurements are assigned to each track.

\section{Track smoothing}

In track smoothing step, the latest track prediction is combined with the associated plot to provide a new, improved estimate of the target state as well as a revised estimate of the errors in this prediction

\section{Data (Measurements to Track) Association}

The radar tracker seeks to determine which plots should be used to update which tracks. Typically, given plot can only be used to update one track. In these applications, a plot can be used to update several tracks, recognizing the uncertainty in knowing to which track the plot belongs.

Schematic diagram describes basic track management process, given in Fig.6.
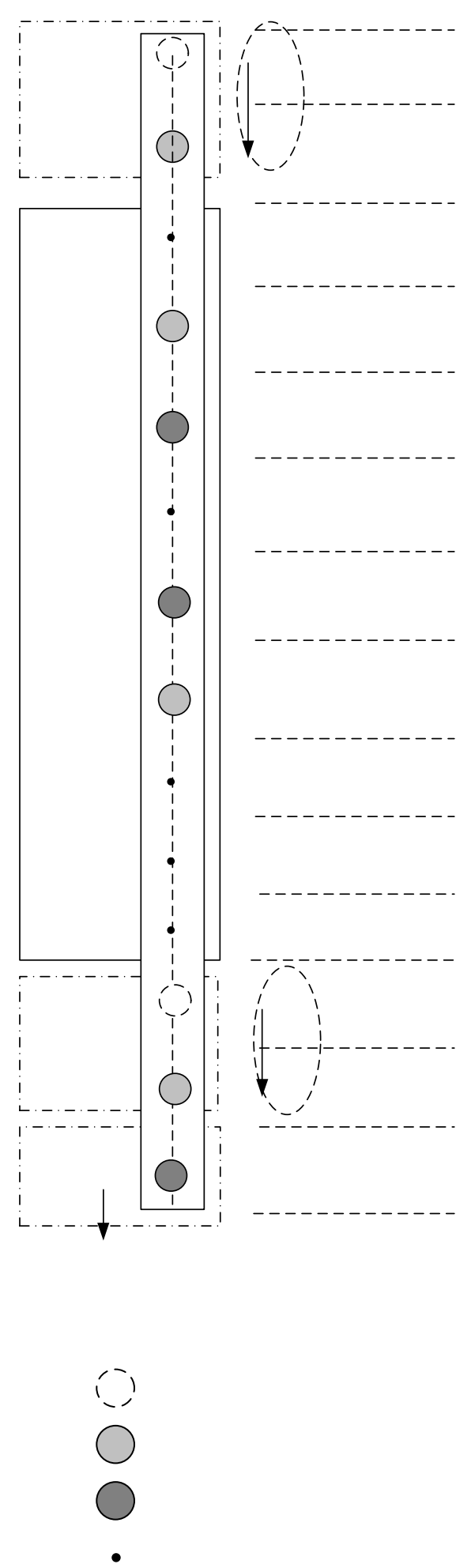

Figure 6. Schematic diagram of track status management 


\section{Results of Simulation}

For the purpose of the simulation, the scenario with six targets has been selected (Fig.7). Targets are moving straight or with a maneuver. The sampling period of radar sensor is $T=1$ s. Duration of the scenario is 50 scans. The target moves in the region $\mathrm{x}=[0 ; 1000], \mathrm{y}=[0 ; 500]$ and can appear or disappear in the scene at any time. The target states consist of positions and velocities and move according to the linear and Gaussian target dynamics [15].

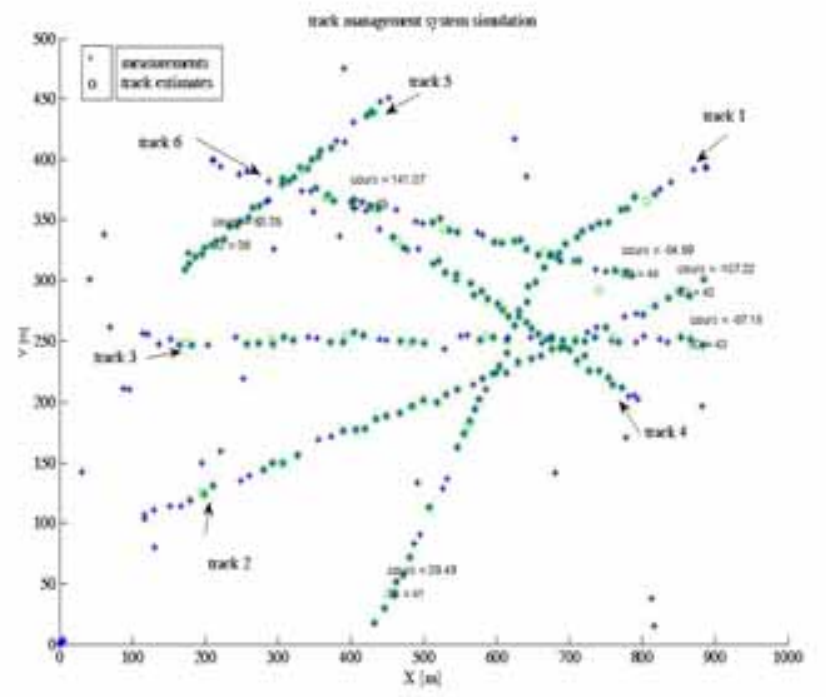

Figure 7. Simulation of track management system with six targets

The system input is modeled as follows: $X=\left[\begin{array}{llll}x & \dot{x} & y & \dot{y}\end{array}\right]$ vector state where $x, y$ are the Cartesian coordinates of the target position, $\dot{x}, \dot{y}$ are the appropriate velocities. Transition matrix $\left(F_{C V}\right.$ - constant velocity model and $F_{C T}$ - coordinate turn model) and process noise matrix are given by:

$$
\begin{gathered}
F_{C V}=\left[\begin{array}{llll}
1 & T & 0 & 0 \\
0 & 1 & 0 & 0 \\
0 & 0 & 1 & T \\
0 & 0 & 0 & 1
\end{array}\right] \\
F_{C T}=\left[\begin{array}{cccc}
1 & \frac{\sin (\omega t)}{\omega} & 0 & \frac{\cos (\omega t)-1}{\omega} \\
0 & \cos (\omega t) & 0 & -\sin (\omega t) \\
0 & \frac{1-\cos (\omega t)}{\omega} & 1 & \frac{\sin (\omega t)}{\omega} \\
0 & \sin (\omega t) & 0 & \cos (\omega t)
\end{array}\right] \\
\mathbf{Q}(k)= \\
{\left[\begin{array}{cccc}
T^{3} / 3 & T^{2} / 2 & 0 & 0 \\
T^{2} / 2 & T & 0 & 0 \\
0 & 0 & T^{3} / 3 & T^{2} / 2 \\
0 & 0 & T^{2} / 2 & T
\end{array}\right]}
\end{gathered}
$$

respectively, $\omega=0.075[\mathrm{rad} / \mathrm{s}]$ is an angle velocity, where $q=0.0052$ is a maneuver coefficient. The measurement noise is also independent of the process noise. The probability of detection is assumed almost unity. Examined probability of detections is $\mathrm{P}_{D}=0.9$. Clutter is uniformly distributed over the observation space with an average rate of 5 points per scan. Results of the numerical simulation are shown in Fig.7. During 50 scans of simulation scenario, six (6) targets move on random trajectories, combined with straight line motion (targets 2, 3, 4 and 5) and with maneuver (targets 1 and 6). Measurements and target state estimates are given. The numerical simulation showed justification of using the proposed system.

\section{Conclusions}

In this paper, we present the concept of track management procedure for the target tracking system from " $\mathrm{C}$ " band family radars. The proposed TMS system is numerical tested and could be applied for modernization of a radar GIRAFFE. It is also proposed that it could be applied into SDR. The principle of software defined radar is (in brief) presented. A complete track management procedure, which is proposed for target tracking application in the modernized radar GIRAFFE, is presented. Also, schematic diagram and description of all track status parameters is given. Whole target tracking procedure is tested by the computer simulation. Results of simulation, given in the paper, show that the proposed TMS procedure has a good target tracking performance.

\section{References}

[1] BLACKMAN,S.: Multiple-target tracking with radar applications, Artech House, 1986.

[2] SINGER,R.: Estimate optimal tracking filter performance for manned maneuvering targets, IEEE Trans. Aerospace and Electronic Systems, July 1970, Vol.6, No.4, pp.473-483.

[3] REID,D.B.: An Algorithm For Tracking Multiple Targets, IEEE Transactions on Automatic Control, December 1979, Vol.AC-24, pp.843-854.

[4] IVKOVIC,D., SIMIC,S., DUKIĆ,M., ERIĆ,M.: Design and Implementation of Software Defined Receiver in a Conventional Radar, Proc. of the International Radar Symposium IRS-2005, 06-08. September 2005, Berlin, Germany, Proceedings, ISBN: 978-373-699343-3.

[5] CHALLA,S., EVANS,R., MORELANDE,M., MUŠICKI,D.: Fundamentals of Object Tracking, Cambridge University Press, 2011.

[6] Available via link: https://en.wikipedia.org/wiki/Giraffe_radar

[7] LIGINBUHL,T., SUN,Y., WILLETT,P.: A Track Management System for the PMHT Algorithm. Proc. of Conference on Data Fusion, Montreal, CANADA, 07.-10. August 2001.

[8] SONG,T.L., MUŠICKI,D., KIM,D.S., RADOSAVLJEVIĆ,Z.: Gaussian mixtures in multi-target tracking: a look at Gaussian Mixture Probability Hypothesis Density and Integrated Track Splitting, IET Proceedings: Radar, Sonar and Navigation, ISSN 1751-8784, 2012, Vol.6, No.5, pp.359-364.

[9] IVKOVIĆ,D., ANDRIĆ,M., ZRNIĆ,B.: Detection of Very Close Targets by Fusion CFAR Detectors, Scientific Technical Review, ISSN 1820-0206, 2016, Vol.66, No.3, pp.50-57.

[10] IVKOVIĆ,D., ANDRIĆ,M., ZRNIĆ,B., OKILJEVIĆ,P., KOZIĆ,N.: CATM-CFAR Detector in the Receiver of the Software Defined Radar, Scientific Technical Review, ISSN 1820-0206, 2014, Vol.64, No.4, pp.27-38

[11] RADOSAVLJEVIĆ,Z., MUŠICKI,D.: Limits of target tracking in heavy clutter, $3^{\text {rd }}$ ASIA-Pacific International Conference of Synthetic Aperture Radar APSAR 2011, 26-30. September 2011, Seoul, Republic of Korea, Proceedings, ISBN: 978-899-3246-17-9.

[12] RADOSAVLJEVIC,Z., SONG,T.L., KOVACEVIC,B.: Linear MultiTarget IPF Algorithm for Automatic Tracking, Scientific Technical Review, ISSN 1820-0206, 2016, Vol.66, No.1, pp.3-10.

[13] RADOSAVLJEVIĆ,Z., MUŠICKI,D., KOVAČEVIĆ,B., KIM,W.C., SONG,T.L.: Integrated Particle Filter for Target Tracking, 13th International Conference on Electronics, Information and Communication, ICEIC 2014, 15-18 January 2014, Kota Kinabalu, Malaysia, Proceedings, ISBN: 978-147-9937-97-4.

Received: 25.01.2018. Accepted: 27.03.2018. 


\title{
Jedan pristup uvođenja sistema za upravljanje tragovima $u$ softverski definisanom radaru
}

Svaki sistem za praćenje više ciljeva mora imati proceduru za upravljanje tragovima. Ona je sastavni deo sistema za praćenje i često se koristi zajedno sa postupkom pridruživanja podataka, procenom vektora stanja traga i drugim delovima sistema. Sa druge strane, porodica radara u "C" - opsegu frekvencija, koristi se za osmatranje vazduha od niskih do srednjih nadmorskih visina, dizajnirana da otkriva ciljeve na malim visinama, u uslovima šuma i elektronskih ometača. $U$ radu je takođe predložena implementacija sistema za praćenje ciljeva unutar softverski definisanog radara. U okviru svoje modernizacije, prijemnik je dizajniran kao softverski definisan radio. U radu je opisana procedura postupka sistema upravljanja tragovima u okviru sistema za praćenje više ciljeva. To uključuje potpunu proceduru inicijalizacije, održavanja i brisanja tragova. Deo numeričkih eksperimenata dat je na kraju rada, kako bi se opisala primenljivost i dobra funkcionalnost sistema upravljanja tragovima.

Ključne reči: praćenje cilja, radar za praćenje cilja, softverski definisan radar, sistem za upravljanje tragovima, numerička simulacija, procedura.

\section{Une approche de l'introduction du système pour la détection des traces chez les radars définis par le logiciel}

\begin{abstract}
Chaque système pour le suivi de plusieurs cibles doit avoir une procédure pour la direction des traces. Elle fait partie du système de suivi et elle est souvent utilisée avec le procédé de l'association des données, l'estimation du secteur de l'état de trace et les autres parties du système. D'autre part la famille des radars dans la portée $C$ de fréquence est utilisée pour l'observation de l'air à partir des bases à moyennes altitudes. Elle est conçue pour détecter les cibles à basses altitudes, dans les conditions de bruit et de contre mesures électroniques. Dans ce travail on a proposé aussi l'installation du système pour le suivi des cibles à l'intérieur du radar défini par le logiciel. Dans le cadre de sa modernisation le récepteur a été conçu comme une radio défini par le logiciel. On a décrit la procédure du procédé du système de direction des traces chez le système de suivi de plusieurs cibles. Cela comprend la procédure complète de l'initialisation, le maintien et la délétion des traces. Une partie des essais numériques est présentée à la fin du travail dans le but de décrire la possibilité d'application et le bon fonctionnement du système de la direction des traces.
\end{abstract}

Mots clés: suivi de cible, radar pour le suivi de cible, radar défini par le logiciel, système pour la direction des traces, simulation numérique, procédure.

\section{Один подход к внедрению системы управления трассировкой в радиолокационной станции, определяемой программным обеспечением}

\begin{abstract}
Каждая система для отслеживания нескольких целей должна иметь процедуру для управления трассировкой. Она является неотьемлемой частью системы для отслеживания и часто используется в сочетании с процессом ассоциации данных, оценкой состояния трассировки и другими частями систем. С другой стороны, семейство высокоскоростных импульсных доплеровских поисковых радиолокаторов с диапазоном "Ц"-частот используется для наблюдения воздуха от низких до средних высот над уровнем моря, предназначено для обнаружения маломощных и малосетевых воздушных целей в условиях шума и электронных помех. В документе также предлагается внедрение системы для отслеживания целей в радиолокационной станции определяемой программным обеспечением. В рамках своей модернизации приёмник разработан как радиолокационная станция определяемая программным обеспечением. В этом документе описывается процедура системы управления трассировкой в рамках многоцелевой системы отслеживания. Это включает в себя полную процедуру инициализации, сохранения и удаления следов. Часть численных экспериментов приведена в конце статьи, чтобы описать применимость и хорошие функциональные возможности системы управления трассировкой.
\end{abstract}

Ключевые слова: отслеживание целей, радиолокационная станция для отслеживания целей, радиолокационная станция определяемая программным обеспечением, система управления трассировкой, численное моделирование, процедура. 